\title{
Preventable factors in hospital admissions for asthma
}

Gustavo A Ordoñez, Peter D Phelan, Anthony Olinsky, Colin F Robertson

\begin{abstract}
Asthma remains the second most common cause for admissions to a paediatric hospital bed. The aim of this study was to describe the characteristics of children admitted to hospital with an acute asthma attack and to identify factors that may prevent future hospital admissions. Parents of all children aged 3 to 15 years admitted to hospital for acute asthma were interviewed and the child's case record reviewed. Children were recruited consecutively in two groups: 141 summer/ autumn and 125 winter/spring 1996. According to the pattern of symptoms in the previous 12 months, $61 \%$ of the children had infrequent episodic asthma, $26 \%$ had frequent episodic asthma, and $13 \%$ persistent asthma. Only $8 \%$ of children aged 8 years or less had persistent asthma, in contrast to $22 \%$ of those aged $>8$ years. There was evidence of both inadequate prescription of preventive treatment and poor compliance in the frequent episodic and persistent asthma groups. Of the whole group, $44 \%$ had previously been given an acute asthma management plan, but only $9 \%$ of them used it before the current hospital admission. There was a delay in seeking medical advice ( $>24$ hours after the onset of symptoms) in $27 \%$ of all admissions. This study has identified potential areas where intervention may reduce the number of future admissions. (Arch Dis Child 1998;78:143-147)
\end{abstract}

Keywords: asthma; hospital admission

Asthma remains the second most common cause for admission to a paediatric hospital bed despite extensive educational programmes and an exponential increase in the sales of preventive drugs. The admission rate in Australia has doubled over the past two decades ${ }^{1}$ to a level of $589 / 100000$ per annum in children up to 19 years. The prevalence of childhood asthma in this country has been reported to be between $10 \%$ and $25 \%$ of all children. ${ }^{2}$ This means that between 300000 and 600000 Australian children are affected by the disease. ${ }^{3}$ There is also evidence that the prevalence, severity, and hospital admission rates of asthma in children are increasing in many countries. ${ }^{4}$ The total cost of asthma in Australia in 1991 was in the range of $\$ 585$ to $\$ 720$ million. The value of asthma drugs and appliances used for treatment of the disease in the same year was calculated at over $\$ 120$ million. $^{3}$ Every hospital admission represents a substantial amount in terms of time and money spent by the children and their families, as verified in a recent study relating the cost of childhood asthma to Australian families. ${ }^{5}$ It has been shown that an admission in the previous 12 months is a strong marker of severity and subsequent risk of readmission and death. ${ }^{6-8}$

Several factors have been identified that may influence and possibly prevent admission of children to hospital with an attack of asthma. ${ }^{9}$ These include appropriate preventive treatment, ${ }^{9-15}$ regular review by a physician (at least every three months), ${ }^{16}{ }^{17}$ provision of an individualised written management plan, ${ }^{16} 1819$ adequate early management of asthma in the home, ${ }^{820} 21$ good compliance with preventive treatment, ${ }^{82}$ and an acceptable level of asthma knowledge. ${ }^{16} 23$

The relatively high admission and readmission rates for asthma in children are still of concern. Previous studies have identified one or two preventable factors in isolation, most of them retrospectively. This study describes characteristics distinguishing children admitted for asthma and identifies factors that might prevent future hospital admissions for asthma.

\section{Methods}

Parents of children aged 3 to 15 years admitted with asthma to the Royal Children's Hospital, Melbourne, were prospectively and consecutively recruited in two groups: summer/autumn (February/March) and winter/spring (August/ September) 1996. During the period of the study, only the first visit for each child was analysed. Children were excluded when admitted with asthma combined with other lung disease or concomitant major illness.

All the participants in the study were interviewed using a questionnaire, and the child's case record was reviewed. The questionnaire was designed to obtain demographic data, personal and family history of asthma, medical treatment, asthma general knowledge, and details of the current episode of asthma. When necessary, an interpreter was used. Parents and children were contacted in the ward within 12 hours of hospital admission and invited to participate. Informed written consent was obtained before their inclusion in the study. The study was approved by the Royal Children's Hospital ethics in human research committee.

The functional severity scale of asthma in children, used in this study, ranks the severity of asthma as low, mild, moderate, or severe..$^{24}$ In addition, we described the pattern of asthma in the previous 12 months, as defined by Phelan et $a l .{ }^{15}$ Children with infrequent episodic asthma have isolated episodes of wheeze with an 
Table 1 Details of the personal history of asthma in children admitted to hospital with an exacerbation $(n=266)$

\begin{tabular}{|c|c|c|}
\hline & $\begin{array}{l}\text { No of } \\
\text { children }\end{array}$ & $(\%)$ \\
\hline \multicolumn{3}{|l|}{ Age of asthma onset (years) } \\
\hline $1-3$ & 201 & $(75.6)$ \\
\hline $4-6$ & 51 & $(19.2)$ \\
\hline $7-15$ & 14 & $(5.3)$ \\
\hline \multicolumn{3}{|l|}{ Median $(\mathrm{IQR})=2(2-3)$} \\
\hline \multicolumn{3}{|l|}{ Functional severity scale of underlying asthma } \\
\hline Low & 41 & $(15.4)$ \\
\hline Mild & 79 & $(29.7)$ \\
\hline Moderate & 94 & $(35.3)$ \\
\hline Severe & 52 & $(19.5)$ \\
\hline \multicolumn{3}{|l|}{ Pattern of asthma (previous 12 months) } \\
\hline Infrequent episodic asthma & 162 & $(60.9)$ \\
\hline Frequent episodic asthma & 69 & $(25.9)$ \\
\hline Persistent asthma & 35 & $(13.2)$ \\
\hline \multicolumn{3}{|l|}{ Seasonal pattern of symptoms } \\
\hline Winter & 77 & $(28.9)$ \\
\hline Spring & 14 & (5.3) \\
\hline Summer & 20 & (7.5) \\
\hline Autumn & 10 & $(3.8)$ \\
\hline No pattern & 145 & $(54.5)$ \\
\hline \multicolumn{3}{|c|}{ Asthma attendances in the emergency department in the last 12} \\
\hline months & 144 & $(54.1)$ \\
\hline Hospital admission over the last 12 months & 121 & $(45.5)$ \\
\hline Previous admissions to the intensive care unit & 30 & $(11.3)$ \\
\hline Limitation during exercise (more often than monthly) & 101 & $(38)$ \\
\hline Daily use of $\beta_{2}$ agonists & 73 & (27) \\
\hline \multicolumn{3}{|c|}{$\begin{array}{l}\text { School absenteeism: median number (IQR) of days off school in the past } 12 \text { months because o } \\
\text { asthma symptoms }=7(3-15)\end{array}$} \\
\hline
\end{tabular}

asymptomatic interval of at least four weeks. In frequent episodic asthma the interval is less than four weeks. Children with persistent asthma have symptoms such as sleep disturbance due to cough or wheeze, exercise limitation, or the need for bronchodilators to relieve wheeze in the interval period. Compliance with preventive treatment was classified as poor or good according to a validated four item self reported adherence measure, which has concurrent and predictive validity. ${ }^{25}{ }^{26}$ The current acute episode of asthma was classified as mild, moderate, severe, or very severe according to the clinical severity scale for acute asthma in children. ${ }^{27} 28$ The asthma knowledge questionnaire included in our survey was validated by Fitzclarence and Henry. ${ }^{23}{ }^{29}$ It scores the responses from 0 to 31 and divides the result into a low $(\leqslant 18)$ or a high (>18) level of asthma knowledge. The admission policy was not modified throughout the period of this study.

The following were considered as possibly preventable factors:

(1) Inappropriate preventive treatment: defined as lack of preventive treatment in children with frequent episodic asthma or persistent asthma.

(2) Poor compliance with preventive treatment.

(3) Failure to use the asthma crisis management plan.

(4) A low level of asthma knowledge.

(5) A delay of more than 12 hours in starting $\beta_{2}$ agonists at home after the onset of symptoms for the current asthma episode before the present hospital admission.
Table 2 Preadmission asthma management in 266 children admitted to hospital with an exacerbation

\begin{tabular}{|c|c|c|}
\hline & $\begin{array}{l}\text { No of } \\
\text { patients }\end{array}$ & $(\%)$ \\
\hline \multicolumn{3}{|l|}{ Preventive drugs } \\
\hline Inhaled steroids & 111 & $(42)$ \\
\hline Sodium cromoglycate & 29 & (11) \\
\hline Salmeterol & 27 & (10) \\
\hline Oral steroids & 7 & (3) \\
\hline Theophylline & 3 & (1) \\
\hline None & 128 & (48) \\
\hline Use of spacer with metered dose inhaler & 121 & $(45)$ \\
\hline $\begin{array}{l}\text { Poor compliance (from } 139 \text { children with } \\
\text { preventive treatment) }\end{array}$ & 52 & (37) \\
\hline \multicolumn{3}{|l|}{ Medical attendance for asthma } \\
\hline Regularly (at least every three months) & 114 & (43) \\
\hline Only if wheezy & 136 & (51) \\
\hline Never & 16 & (6) \\
\hline Possession of a written crisis plan & 117 & $(44)$ \\
\hline \multicolumn{3}{|c|}{$\begin{array}{l}\text { Using peak flow meter at home (from } 119 \text { children } \\
\text { older than } 7 \text { years) }\end{array}$} \\
\hline Daily & 7 & (6) \\
\hline During episodes of wheezing & 57 & (48) \\
\hline Never & 55 & (46) \\
\hline $\begin{array}{l}\text { Spirometry over the last year (from } 119 \\
\text { children older than } 7 \text { years) }\end{array}$ & 29 & (24) \\
\hline
\end{tabular}

(6) A delay of more than 24 hours in seeking medical care after starting $\beta_{2}$ agonists at home, despite their use more often than every three hours just before coming to the hospital.

(7) Not using prednisolone before the current admission, in spite of an attack lasting more than 24 hours and using $\beta_{2}$ agonists more often than every three hours just before coming to the hospital.

(8) Not visiting a physician regularly (at least every three months) in children with frequent episodic asthma and persistent asthma.

All the newly diagnosed asthmatics were excluded when analysing these preventable factors.

STATISTICAL ANALYSIS

Percentages were used for categorical variables and medians $(\mathrm{m})$ with the interquartile range (IQR) according to the skewness of continuous data. A non-parametric test (the KruskalWallis test) was used to examine differences between some variables (using the SPSS software). Significance was accepted at the $\mathrm{p}<0.05$ level.

\section{Results}

There were 266 children in the study-141 from February to March and 125 from August to September. Only six parents refused to participate.

DEMOGRAPHIC DATA

The male/female ratio was $173 / 93$ and the median (IQR) age was 7 years $(5-11) ; 64 \%$ of children were less than 9 years old. Ninety seven percent of the children were born in Australia; $54 \%$ had at least one parent who was born outside Australia. The language spoken at home was English in $77 \%$ of these families. However, for $53 \%$ of the parents English was 
Table 3 Details of the current exacerbation in children admitted to hospital because of asthma

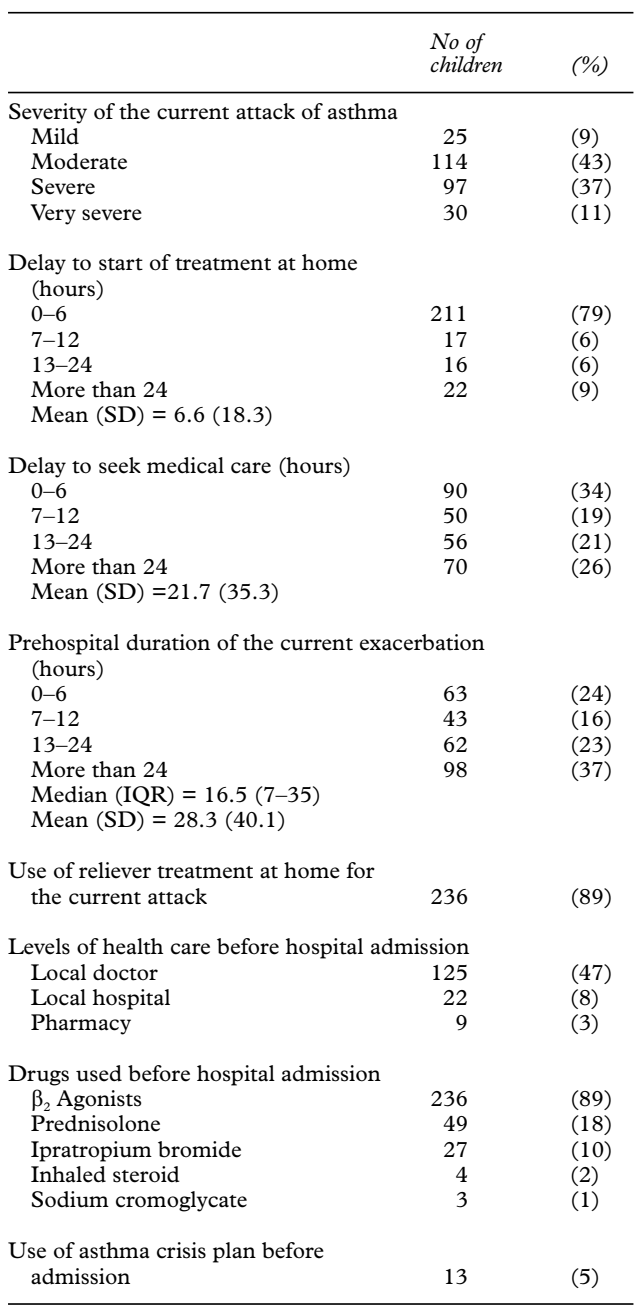

$\mathrm{IQR}=$ interquartile range.

not their first language. A family history of asthma (parents or siblings) was present in $60 \%$ of the families. Almost half $(47 \%)$ of the children were exposed to cigarette smoke at home.

PERSONAL HISTORY OF ASTHMA

Information on the personal history of asthma is shown in table 1. Asthma had been diagnosed previously in $250 / 266(94 \%)$ of the children. The pattern of asthma was influenced by age. Infrequent episodic asthma was more common $(68 \%)$ in young children $(<9$ years old) than older children (48\%). Persistent asthma was much more common in the older children $(22 \% v 8 \%)$.
REGULAR TREATMENT

Information regarding preventive treatment and compliance, use of spacers, written crisis plans, monitoring of lung function, and medical attendances is shown in table 2 .

During the last 12 months, 138 of 266 children $(52 \%)$ had been using preventive treatment on a regular basis (daily) as prescribed by their physicians. Of the 104 children with frequent episodic asthma or persistent asthma, $26(25 \%)$ had been prescribed preventive drugs. Only $51 / 101(50 \%)$ of those children with exercise limitation used any drug before exercising.

\section{MEDICAL REVIEW}

Of those children who had a regular medical review for their asthma ( $\mathrm{n}=114), 50 \%$ attended a general practitioner and the other $50 \%$ visited a specialist (paediatrician, thoracic physician, or allergist). When they had symptoms suggesting an asthma exacerbation, most children $(171 / 266(64 \%))$ visited their local doctor, 47 (18\%) went directly to the hospital, and $16(6 \%)$ attended a specialist. When asked about attendance to non-medical practitioners for asthma care in the last 12 months, 33/266 $(12 \%)$ had consulted a pharmacist, and 32 $(12 \%)$ had visited a naturopath, homoeopath, chiropractor, acupuncturist, or relaxation therapist.

\section{ASTHMA KNOWLEDGE}

The asthma knowledge questionnaire showed a mean (SD) score of 19.9 (5.6); 129 of 266 $(49 \%)$ had a low level of asthma knowledge with a mean score of 15.4 (3.9), while $51 \%$ had a high level of knowledge with a mean score of $24.4(2.1)$.

CURRENT ASTHMA ATTACK AND HOSPITAL

ADMISSION

Details of the current asthma attack and circumstances preceding this hospital admission are shown in table 3.

For 74 children $(28 \%)$ it was the first hospital admission with asthma, while for 16 children, the current exacerbation represented the first diagnosis of asthma. The most common trigger for this attack identified by 194 of 266 parents (73\%) was a "cold", followed by a change in the weather in 56 $(21 \%)$, dust in $21(8 \%)$, and exercise in 15 $(5 \%)$. Very few people referred to tobacco smoke, contact with animals or chemicals, stress, or foods as being trigger factors. In 28 cases $(11 \%)$ there was no trigger identified.

Table 4 Preventable factors in children admitted to hospital and previously diagnosed with asthma $(n=250)$

\begin{tabular}{lc}
\hline & No (\%) of children \\
\hline Failure to use the asthma crisis management plan & $238(95)$ \\
Low level of asthma knowledge & $128(51)$ \\
Inappropriate preventive treatment & $77(31)$ \\
Poor compliance with preventive treatment & $52(21)$ \\
Not using prednisolone before the current admission, in spite of an attack lasting >24 h and use of $\beta_{2}$ & $44(18)$ \\
$\quad$ agonists more often than every $3 \mathrm{~h}$ just before coming to hospital & $41(16)$ \\
Not visiting a physician regularly (at least every three months) in children with FEA and PA & $37(15)$ \\
Delay of $>12 \mathrm{~h}$ in starting $\beta_{2}$ agonists at home after onset of asthma symptoms & \\
Delay of $>24 \mathrm{~h}$ in seeking medical care after starting $\beta_{2}$ agonists at home, despite their use more often than & $26(10)$ \\
$\quad$ every $3 \mathrm{~h}$ just before coming to hospital &
\end{tabular}

FEA = frequent episodic asthma; $\mathrm{PA}=$ persistent asthma. 
The majority of children-93\% (232/250) of those previously diagnosed as asthmatic - used specific anti-asthma drugs during the current asthma exacerbation: $173 / 250$ children (69\%) used nebulised $\beta_{2}$ agonists, 34 (14\%) used inhaled $\beta_{2}$ agonists with a spacer device, and 16 $(6 \%)$ used metered dose inhalers without spacers. There were also six children $(2.5 \%)$ who used an oral $\beta_{2}$ agonist preparation.

Of those children with a bronchodilator at home, $60 \%(149 / 250)$ used them one to two hourly, while $27 \%$ used them every three to four hours. Surprisingly, only 10/117 (9\%) of families possessing an asthma crisis plan at home actually used it.

PREVENTABLE FACTORS FOR ADMISSION TO HOSPITAL

Factors that may have prevented an admission to hospital are shown in table 4 . From the eight possible preventable factors, $98 \%$ of the population previously diagnosed with asthma had at least one preventable factor, and $85 \%$ had three or more. The number of preventable factors was significantly greater in children with frequent episodic asthma and persistent asthma $(\mathrm{p}<0.001)$.

\section{Discussion}

An admission to hospital is one of the most serious consequences of asthma. ${ }^{4}$ Every hospital admission generates stress, anxiety, and interruption to the normal lifestyle of children and their parents, as well as high costs for the health care system and the family. ${ }^{9} 10$ The purpose of this prospective study was to describe the characteristics of children admitted to hospital with an acute asthma attack and to identify factors which may prevent future hospital admission for an acute exacerbation of asthma.

The majority of children admitted to hospital with an acute asthma attack in this study had infrequent episodic asthma. Almost half had a previous attendance to an emergency department review or a hospital admission in the last 12 months. School absenteeism, sleep disturbance, or exercise inducing wheezing were also common. Furthermore, there was evidence suggesting suboptimal asthma control and poor use of self management strategies in each of the three patterns of asthma. The group of children with frequent episodic asthma and persistent asthma also had evidence of inadequate use of preventive treatment. Interestingly, $98.4 \%$ of the population studied had at least one of the eight possible factors that we thought likely to prevent future hospital admissions.

Previous studies in the general community have documented the functional severity of asthma to be low and mild in $77 \%$ of children. ${ }^{1524}$ In contrast, the population included in this study had a higher proportion within the bands of moderate to severe asthma. Our finding that $13 \%$ of children had persistent asthma is more than expected for the general childhood population-Phelan et al quote $5 \% .{ }^{15}$ The proportion of children with persistent asthma admitted with an acute exacerbation was 2.6-fold higher in children older than 8 years.

In this study we proposed eight factors that could contribute and potentially prevent future hospital admissions in asthmatic children. A large proportion $(72 \%)$ of children, previously diagnosed with asthma, had between two and four preventable factors. Children with more frequent exacerbations and interval symptoms had more of these factors. This suggests that children classified with frequent episodic or persistent asthma would be more likely to benefit from programmes focusing on prevention.

The treatment of airway inflammation in asthma with preventive drugs (inhaled steroids, sodium cromoglycate) is recognised to be important in decreasing morbidity and the number of hospital admissions. ${ }^{10-13} 18$ Some studies have shown poor control and suboptimal treatment preceding the attendance to the emergency service, perhaps contributing to the acute crisis. ${ }^{91416}$ Recent asthma management guidelines suggest that children with frequent episodic asthma and persistent asthma should be treated with preventive drugs. ${ }^{30}$ According to these guidelines, a quarter of the children in this study with frequent episodic asthma and persistent asthma were undertreated. Control of interval symptoms is largely dependent on compliance with appropriate drug treatment. ${ }^{22}$ Adherence to treatment regimens has been measured in several studies, using objective and subjective methods, ${ }^{25}$ and estimates of satisfactory adherence vary between $10 \%$ and $50 \% .{ }^{31}$ In this study $60 \%$ of the children had good subjective compliance. However, only $39 \%$ of children had frequent episodic asthma and persistent asthma.

Several studies have indicated that at least one third of the hospital admissions are in some way related to improper actions taken by the patient, his family, or the health care professional. $^{22} 32$ One of the strategies promoted to manage exacerbations is the need for parents and patients to have an action plan. ${ }^{61619}{ }^{33-35}$ These individualised written instructions have become an integral part of self management and contain information on how to detect the early stages of an asthma attack and what action needs to be taken. ${ }^{18}$ In the present study, $95 \%$ of families did not use any written instructions during the current attack. Although $44 \%$ had previously been given an acute asthma management plan, only $9 \%$ of them used it before the current hospital admission. Health professionals involved in the management of asthmatic children should consider strategies to provide a more attractive, practical, and handy written crisis plan to improve and motivate parents and patients to use it.

Concern has recently been expressed over the need for asthmatics with acute attacks to receive intensive initial management, ${ }^{819}$ including optimal bronchodilator treatment, steroids in the form of oral prednisolone when included by the doctor in the crisis plan, early recognition of signs suggesting a worsening attack, and prompt evaluation by physicians to 
avoid more severe exacerbations requiring unavoidable admissions. As in a recent study on near fatal asthma in childhood, ${ }^{8}$ there was a group of children in our study in whom there was a delay in starting reliever drugs and seeking medical help. We found that $18 \%$ of children previously diagnosed with asthma and with an exacerbation lasting more than 24 hours used bronchodilators more often than every three hours and no systemic corticosteroids before the current hospital admission. This is similar to a previous study on the prehospital management of children with acute asthma. ${ }^{20}$

Several publications have stressed the importance for asthmatic children of visiting a physician regularly. ${ }^{13}{ }^{16}$ Such visits may have a positive effect in promoting periodic evaluation of asthma severity and its treatment, monitoring lung function when feasible, improving compliance and proficiency with the use of drugs, and instructing parents and patients about taking adequate measures to reduce exposure to allergens and irritants. However, the results in our study showed that $40 \%$ of children with frequent episodic asthma and persistent asthma did not have a regular medical review. Furthermore, only $40 \%$ of the children in these categories and older than 7 years had had lung function tests in the previous year.

In this study population, $69 \%$ of those with previously diagnosed asthma had used a nebuliser at home for administration of $\beta_{2}$ agonists. The use of home nebulisers for $\beta_{2}$ agonists has been established for many years as part of the management of asthma in the community. This practice has continued in spite of the increasing evidence in favour of the combination of metered dose inhaler and a holding chamber for the management of acute asthma. ${ }^{36}$ Current paediatric teaching is attempting to address the issue in this country, popularising the benefits of the use of a metered dose inhaler and holding chamber.

This prospective study has identified several well known preventable factors for asthma hospital admissions, including some that are the cornerstone of the asthma treatment plan-that is, the early use of bronchodilators and oral prednisolone, and early medical consultation. We have shown that treatment plans are underused by doctors, but we are more concerned by the fact that when issued they are often not followed by patients. There is a need to evaluate different strategies to improve patients' use of treatment plans.

1 Robertson CF, Sennhauser FH, Mallol J. The change in prevalence and severity of asthma in developed and developing countries. Baillieres Clin Paediatr 1995;3:253-76.

2 Peat JK, Vandemberg RH, Green WF, et al. Changes in prevalence of asthma in Australian children. BMF 1994; 308:1591-6.

3 Boston Consulting Group. Report on the cost of asthma in Australia. Melbourne: National Asthma Campaign, 1992.

4 Kun HY, Oates RK, Mellis CM. Hospital admissions and attendances for asthma - a true increase? Med F Aust 1993; 159:312-3.
5 Toelle GT, Peat JK, Mellis CM, et al. The cost of childhood Toelle GT, Peat JK, Mellis CM, et al. The cost of childhood
asthma to Australian families. Pediatr Pulmonol 1995;19:
$330-5$.

6 Mitchell EA, Bland JM, Thompson JMD. Risk factors for readmission to hospital for asthma in childhood. Thorax 1994;49:33-6.

7 Mitchell EA, Burr D. Comparison of the characteristics of children with multiple admissions to hospital for asthma with those with a single admission. NZ Med f 1987;100: $736-8$.

8 Martin AJ, Campbell DA, Gluyas PA, et al. Characteristics of near fatal asthma in childhood. Pediatr Pulmonol 1995;20:1-8.

9 Greenberger P. Preventing hospitalisations for asthma by improving ambulatory management. Am 7 Med 1996;100: 381-2.

10 Wennergren G, Kristjánsson S, Strannegard IL. Decrease in hospitalisation for treatment of childhood asthma with increased use of antiinflammatory treatment, despite an increase in the prevalence of asthma. F Allergy Clin Immunol 1996;97:742-8.

11 Sears MR, Taylor R, Print CG, et al. Increased inhaled bronchodilator vs increased inhaled corticosteroid in the control of moderate asthma. Chest 1992;102:1709-15.

12 Griffiths C, Naish J, Sturdy P, et al. Prescribing and hospital admissions for asthma in east London. BMF 1996;312: 481-2.

13 Warner JO, Neijens HJ, Landau LI, et al. Asthma: a follow up statement from an international paediatric asthma consensus group. Arch Dis Child 1992;67:240-8.

14 Bauman A, Mitchell CA, Henry RL, et al. Asthma morbidity in Australia: an epidemiological study. Med f Aust 1992; 156:827-31.

15 Phelan PD, Olinsky A, Oswald H. Asthma: classification, clinical patterns and natural history. Baillieres Clin Paediatr 1995;3:307-18.

16 Dales RE, Kerr PE, Schweitzer I, et al. Asthma management preceding an emergency department visit. Arch Intern Med 1992;152:2041-4.

17 Price JF. The management of chronic childhood asthma. In: Silverman M, ed. Childhood asthma and other wheezing disorders. London: Chapman and Hall Medical, 1995:35774

18 Garret J, Kolbe J, Richards G, et al. Major reduction in asthma morbidity and continued reduction in asthma mortality in New Zealand: what lessons have been learned? Thorax 1995;50:303-11.

19 Gillies J, Barry D, Crane J, et al. A community trial of a written self management plan for children with asthma. $N Z$ Med f 1996;109:30-3.

20 Dawson KP, Jandera E, Penna C. The prehospital management of children with acute asthma. $\mathcal{F}$ Paediatr Child Health 1992;28:321-2.

21 Woolcock A, Rubinfeld AR, Seale JP, et al. Thoracic Society of Australia and New Zealand Asthma management plan 1989. Med f Aust 1989;151:650-3.

22 Fireman P, Friday GA, Gira C, et al. Teaching self management skills to asthmatic children and their parents in an ambulatory care setting. Pediatrics 1981;68:341-8.

23 Gibson PG, Henry RL, Vimpani, et al. Asthma knowledge, attitudes, and quality of life in adolescents. Arch Dis Child 1995;73:321-6

24 Rosier MJ, Bishop J, Nolan T, et al. Measurement of functional severity of asthma in children. Am $\mathcal{F}$ Respir Crit Care Med 1994;149:1434-41.

25 Morisky DE, Green LW, Levine DM. Concurrent and predictive validity of a self reported measure of medication adherence. Med Care 1986;24:67-74.

26 National Asthma Education Program Coordinating Committee. Expert panel on the management of asthma Patient education. F Allergy Clin Immunol 1991;88:460-72.

27 Bishop J, Carlin JB, Nolan T. Evaluation of the properties and reliability of a clinical severity scale for acute asthma in children. F Clin Epidemiol 1992;45:71-6.

28 Yung $M$, South M, Byrt T. Evaluation of an asthma severity score. $\mathcal{F}$ Paediatr Child Health 1996;32:261-4.

29 Fitzclarence CAB, Henry RL. Validation of an asthma knowledge questionnaire. f Paediatr Child Health 1990;26: $200-4$.

30 Phelan PD. Asthma in children. An overview. Baillieres Clin Paediatr 1995;3:247-52.

31 Lask B. Psychological factors. In: Silverman M, ed. Childhood asthma and other wheezing disorders. London: Chapman and Hall Medical, 1995:421-8.

32 Palm CR, Murcek MA, Roberts TR, et al. A review of asthma admissions and deaths at Children's Hospital of Pittsburgh from 1935 to 1968. F Allergy 1970:46:257.

33 Warner JO, Gotz M, Landau LI, et al. Management of asthma: a consensus statement. Arch Dis Child 1989;64: 1065-79.

34 Warner JO, Neijens HJ, Landau LI, et al. Asthma: a follow up statement from an international paediatric asthma consensus group. Arch Dis Child 1992;67:240-8

35 Racheleffsky GS. Review of asthma self management programme. f Allergy Clin Immunol 1987;80:506-11.

36 Newhouse MT. Emergency department management of life-threatening asthma. Are nebulizers obsolete? Chest 1993;103:661-2. 